\title{
Invasive Pulmonary Aspergillosis Presenting with Tracheobronchial Involvement
}

\author{
Hisako Kushima ${ }^{1,2}$, Issei Tokimatsu ${ }^{3}$, Hiroshi Ishii $^{2}$ and Jun-ichi Kadota ${ }^{1}$ \\ Key words: invasive pulmonary aspergillosis, invasive tracheobronchial aspergillosis, bronchoscopy
}

(Intern Med 55: 1679, 2016)

(DOI: 10.2169/internalmedicine.55.6822)

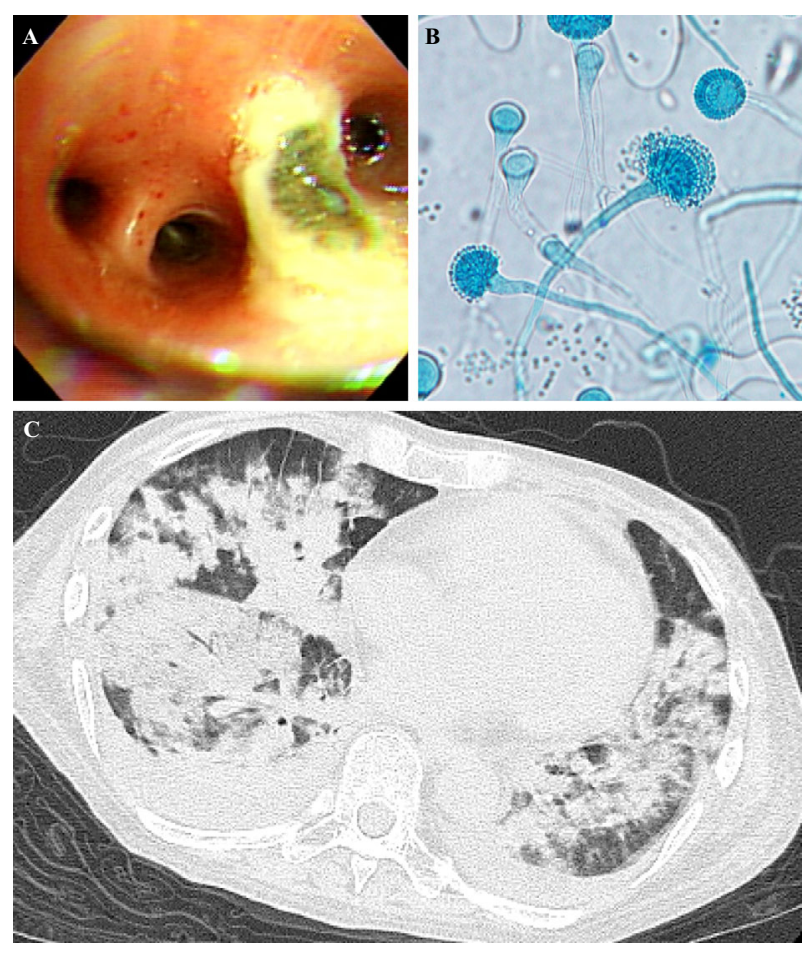

Picture.

A 44-year-old female was admitted to our hospital due to pyrexia and an abnormal chest shadow during treatment with an oral corticosteroid for eosinophilic pneumonia. The serum levels of $\beta$-D-glucan and galactomannan antigen were elevated, but the precipitating antibodies to Aspergillus were negative. Bilateral non-segmental consolidations were observed on chest images. Bronchoscopy showed multiple mucosal lesions with central ulceration (Picture A), which extended from the trachea to the bilateral bronchus. Fungal filaments were observed in a bronchial biopsy specimen, and Aspergillus fumigatus was cultured (Picture B; lactophenol cotton blue stain). Despite the administration of caspofungin, voriconazole and liposomal amphotericin-B, the patient died of acute respiratory distress syndrome (Picture $\mathrm{C}$ ). Angioinvasion is the most common characteristic of aspergillosis in immunocompromised patients, and the presence of tracheobronchial lesions is a general manifestation of aspergillosis in lung transplant recipients $(1,2)$. We herein report a rare case of invasive pulmonary aspergillosis with tracheobronchial involvement in a patient with eosinophilic pneumonia who was receiveing corticosteroids.

The authors state that they have no Conflict of Interest (COI).

\section{References}

1. Krenke R, Grabczak EM. Tracheobronchial manifestations of Aspergillus infections. ScientificWorldJournal 11: 2310-2329, 2011.

2. Logan PM, Primack SL, Miller RR, et al. Invasive aspergillosis of the airways: radiographic, CT, and pathologic findings. Radiology 193: 383-388, 1994.

\footnotetext{
${ }^{1}$ Department of Respiratory Medicine and Infectious Diseases, Oita University Faculty of Medicine, Japan, ${ }^{2}$ Department of Respiratory Medicine, Fukuoka University Hospital, Japan and ${ }^{3}$ Department of Infection Control and Prevention, Kobe University Hospital, Japan Received for publication November 12, 2015; Accepted for publication December 27, 2015

Correspondence to Dr. Hisako Kushima, hkushi@fukuoka-u.ac.jp

(C) 2016 The Japanese Society of Internal Medicine Journal Website: http://www.naika.or.jp/imonline/index.html
} 